\title{
Evaluation of high throughput gene expression platforms using a genomic biomarker signature for prediction of skin sensitization
}

\author{
Andy Forreryd, Henrik Johansson, Ann-Sofie Albrekt and Malin Lindstedt ${ }^{*}$
}

\begin{abstract}
Background: Allergic contact dermatitis (ACD) develops upon exposure to certain chemical compounds termed skin sensitizers. To reduce the occurrence of skin sensitizers, chemicals are regularly screened for their capacity to induce sensitization. The recently developed Genomic Allergen Rapid Detection (GARD) assay is an in vitro alternative to animal testing for identification of skin sensitizers, classifying chemicals by evaluating transcriptional levels of a genomic biomarker signature. During assay development and biomarker identification, genome-wide expression analysis was applied using microarrays covering approximately 30,000 transcripts. However, the microarray platform suffers from drawbacks in terms of low sample throughput, high cost per sample and time consuming protocols and is a limiting factor for adaption of GARD into a routine assay for screening of potential sensitizers. With the purpose to simplify assay procedures, improve technical parameters and increase sample throughput, we assessed the performance of three high throughput gene expression platforms - nCounter ${ }^{\oplus}$, BioMark HD' ${ }^{\mathrm{TM}}$ and OpenArray ${ }^{\circledR}$ - and correlated their performance metrics against our previously generated microarray data. We measured the levels of 30 transcripts from the GARD biomarker signature across 48 samples. Detection sensitivity, reproducibility, correlations and overall structure of gene expression measurements were compared across platforms.

Results: Gene expression data from all of the evaluated platforms could be used to classify most of the sensitizers from non-sensitizers in the GARD assay. Results also showed high data quality and acceptable reproducibility for all platforms but only medium to poor correlations of expression measurements across platforms. In addition, evaluated platforms were superior to the microarray platform in terms of cost efficiency, simplicity of protocols and sample throughput.

Conclusions: We evaluated the performance of three non-array based platforms using a limited set of transcripts from the GARD biomarker signature. We demonstrated that it was possible to achieve acceptable discriminatory power in terms of separation between sensitizers and non-sensitizers in the GARD assay while reducing assay costs, simplify assay procedures and increase sample throughput by using an alternative platform, providing a first step towards the goal to prepare GARD for formal validation and adaption of the assay for industrial screening of potential sensitizers.
\end{abstract}

Keywords: Genomic biomarker signature, GARD, Microarrays, nCounter ${ }^{\oplus}$, BioMark HD ${ }^{\mathrm{TM}}$, OpenArray ${ }^{\oplus}$

* Correspondence: Malin.lindstedt@immun.Ith.se

Department of Immunotechnology, Lund University Medicon, Village 406, Scheelevägen 2, 22381 Lund, Sweden 


\section{Background}

Allergic contact dermatitis (ACD) is characterized by redness of the skin, accompanied by periodic and recurrent episodes of itching [1]. The disease is a type IV delayed type hypersensitivity reaction initiated and mediated by cytotoxic CD8+ T cells and CD4+ Th1 cells [2] and develops upon repeated or prolonged exposure to contact allergens [3]. With a prevalence of 15-20\% [4,5], ACD has rapidly become a major occupational and environmental health problem [6,7]. ACD is a chronic condition and the recommendation to affected individuals is complete avoidance of inducing contact allergen [3].

Contact allergens capable of inducing ACD are termed skin sensitizers. An important group of skin sensitizers are chemical compounds present in common household products such as cosmetics and personal care products. To limit and control the use of sensitizers in such products, chemicals are regularly screened for their capacity to induce sensitization. Historically, such assays have relied exclusively on animal experimentation, with the murine local lymph node assay (LLNA) [8] being the preferred method. However, as of March 2013, an EU legislation [9] imposed a ban on the use of animals for safety assessment of cosmetic products, regardless of the availability of nonanimal test as an alternative to animal testing. Thus, the demand for alternative in vitro methods for prediction of chemical sensitization is urgent.

Recently, we developed the Genomic Allergen Rapid Detection (GARD) assay, a novel alternative to animal testing for identification and risk assessment of human skin sensitizing chemicals using a predictive genomic biomarker signature termed the GARD prediction signature (GPS) [10]. The GPS was established using a panel of reference chemicals comprising 18 well known sensitizers and 20 non-sensitizers. By stimulating the myeloid cell line MUTZ-3 with the panel of reference chemicals, we were able to identify the 200 most potent discriminatory transcripts between non-sensitizers and sensitizers. The information given by differentially expressed transcripts in the GPS was used to train a support vector machine model (SVM) [11]. Subsequently, the SVM model is used for classification of unknown chemical compounds as either sensitizers or non-sensitizers.

The technical format currently used for transcriptional analysis in the GARD assay is Affymetrix ${ }^{\circ}$ wholetranscriptome microarrays. The array platform has been valuable during assay development to identify differentially regulated genes in the GPS from the entire transcriptome, yet it suffers from drawbacks in terms of low sample throughput, high cost per sample and time consuming protocols. Furthermore, the microarray platform has known limitations in terms of sensitivity, reproducibility and dynamic range [12-15]. For an in vitro method to be used for regulatory purposes and eventually for industrial screening of sensitizers, it needs to be validated according to internationally recognized procedures [16]. With the purpose to prepare GARD for formal validation under the supervision of The European Union Reference Laboratory for alternatives to animal testing (EURL ECVAM), and in order to simplify assay procedures, improve technical parameters and increase sample throughput, the GARD assay would benefit from a technical platform transfer. The number of available technologies for high throughput quantitative transcriptome analysis is steadily increasing, but only a handful of comparisons between gene expressions measurements on various platforms exist. Thus, there is a need to evaluate and compare results obtained from the various technologies to assess reliability and biological significance of measurements. We performed a systematic head to head comparison to assess the performance of three of the most prominent high throughput gene expression platforms, including the nCounter ${ }^{\circ}$ analysis system (NanoString ${ }^{\circ}$ technologies) [17], BioMark HD $^{\mathrm{mm}}$ system (Fluidigm ${ }^{\circ}$ corporation) [18] and the OpenArray ${ }^{\circ}$ system (Life Technologies ${ }^{\mathrm{Tm}}$ ) [19]. The nCounter ${ }^{\circ}$ analysis system is a novel hybridization based technology enabling gene expression measurements to be performed directly from cell lysate. The technology use transcript specific color coded molecular probe pairs to capture and count individual transcripts and has several advantages in comparison to microarray platform including easy protocols, less hands-on time and higher sample throughput [17]. BioMark HD HD $^{\mathrm{m}}$ and OpenArray ${ }^{\circ}$ are RT-qPCR based technologies which is considered as the gold standard for quantitative transcription analysis due to its high sensitivity, high reproducibility and large dynamic range [19-21]. RT-qPCR is however a low throughput technology in its conventional format. Utilizing slightly different strategies, both BioMark $\mathrm{HD}^{\mathrm{in}}$ and the OpenArray ${ }^{\circ}$ system provides technologies that aims to conserve the intrinsic analytical benefits of the conventional RT-qPCR while enabling gene expression measurement in a high throughput format [22]. Both systems use streamlined protocols that enable progression from cDNA into results in less than three hours for the OpenArray system and less than seven hours for the BioMark $\mathrm{HD}^{\mathrm{rum}}$ system. In this report, we present a per application relevant comparison and evaluation of the nCounter ${ }^{\circ}$, BioMark $\mathrm{HD}^{\mathrm{m}}$ and the OpenArray ${ }^{\circ}$ platforms in the context of the GARD assay. This report is not intended to serve as a general recommendation of a particular platform, but rather to investigate the trade-offs in terms of price, throughput, protocols, analytical performance and applicability of a selection of high throughput platforms for the GARD assay. Primary focuses were to compare non-technical parameters such as sample throughput, price per sample and simplicity of protocols between the platforms as well as to evaluate the more technical parameters in terms of precision and data 
consistency within each platform, to assess inter-platform consistency, and to determine if transcriptional analysis performed on the evaluated platforms could be applied to the GARD model to classify sensitizers from nonsensitizers. In conclusion, we found that it was possible to achieve acceptable detection sensitivity, reproducibility and discriminatory power of the GARD assay while at the same time simplify assay procedures and reduce assay cost when using any of the suggested high-throughput platforms evaluated in this study.

\section{Results}

Biological model for evaluation of high throughput platforms and phenotypic analysis of unstimulated MUTZ-3 cells

The GARD assay was chosen as a biological model to achieve a per application relevant assessment of the performance of selected high throughput platforms. The cell line used in the GARD assay is the dendritic cell (DC)-like human myeloid leukemia-derived cell line MUTZ-3 [23]. Analogous to primary DCs, MUTZ-3 cells express CD1a, HLA-DR, CD54, CD80 and CD86. The MUTZ-3 population also consists of subpopulations of CD14+, CD34+ and double negative cells as previously described [24]. Phenotypic analysis of cells was performed prior to each round of stimulation to ensure that MUTZ-3 cells were in an immature stage. Cell surface expression levels of the markers CD54, CD86, CD80, HLA-DR, CD14, CD34 and CD1a were verified using flow cytometry prior to stimulations. Results are illustrated in Table 1 and correlated with previously published examples of phenotypic profiles for the MUTZ-3 cells [10].

Inducible up-regulation of CD86 cell surface marker in response to stimulation of MUTZ-3 with skin sensitizers

To enable a comprehensive evaluation between platforms, a panel of 16 chemical compounds including eight sensitizers and eight non-sensitizers initially being used to define the GARD prediction signature (GPS) were prepared for stimulation of MUTZ-3 cells (Table 2). Each stimulation

Table 1 Phenotype of MUTZ-3 cells

\begin{tabular}{lcc}
\hline Cell surface marker & \% positive cells & Standard deviation \\
\hline CD1a & 28.4 & 2.1 \\
CD14 & 6.1 & 0.9 \\
CD34 & 57.0 & 6.2 \\
CD54 & 72.1 & 1.8 \\
CD80 & 0.4 & 0.2 \\
CD86 & 27.8 & 1.8 \\
HLA-DR & 87.4 & 4.1
\end{tabular}

Expression levels of the cell surface markers CD54,CD80,CD86,HLA-DR,CD1a, CD14 and CD34 were determined using flow cytometry to ensure proliferating cells were not differentiated. Results illustrates average percentage of positive cells together with standard deviation $(n=3)$. was performed in biological triplicates, generating a dataset comprising 48 chemical stimulations. The GARD assay uses the inducible cell surface expression of CD86 after chemical stimulation as a general measure of the maturity state of the cells and as a quality control to ensure bioavailability of chemical stimulations. Cell surface expression of CD86 was confirmed after $24 \mathrm{~h}$ of stimulation with chemicals using flow cytometry (Figure 1). CD86 was significantly up-regulated on cells stimulated with the sensitizers 2-hydroxyethyl acrylate, 2-aminophenol, 2nitro-1,4-phenylendiamine and p-phenylendiamine in comparison to vehicle controls. None of the non-sensitizers induced a significant up-regulation of CD86. The outcome of the experiment correlated with previously published data [10].

\section{Transcriptional profiling of MUTZ-3 using high throughput gene expression platforms}

Selection of transcripts for this study was performed in two consecutive steps. In a first step, transcripts were selected in order to obtain a representative expression profile from the GPS to allow for a decisive evaluation of technical parameters such as intra platform reproducibility and limit of detection. In this step, transcripts were selected to cover the whole dynamic range of gene expression present in the original GPS (including low, medium and highly expressed transcripts) as well as to include heavily regulated transcripts, weakly regulated transcripts and to include both up- and down regulated transcripts when comparing expression profiles of chemically stimulated cells to nonstimulated cells. For the transcripts selected in the first step, a second round of selection was performed to include only the most potent predictor genes to allow for assessment of the biological relevance of gene expression data in terms of the GARD assay. Selection of the most potent predictor genes were based on validation call frequencies as described in [10]. The abundance of each transcript included in this study (Table 3) was determined on all platforms using samples from the same cellular stimulation. Data were analyzed to evaluate intra-platform reproducibility, inter-platform reliability and relevance of data produced on each platform for construction of a predictive model for skin sensitization in the GARD assay. A schematic view of the experimental workflow from chemical stimulation to mRNA quantification using the various platforms is illustrated in Figure 2. The data from the high throughput platforms were compared to Affymetrix ${ }^{\odot}$ microarray data from a previous study [10]. A comparison of non-technical parameters of evaluated platforms is illustrated in Table 4.

\section{Preprocessing of data}

Gene expression data obtained on evaluated platforms were normalized prior to any analysis as described in 
Table 2 List of chemical compounds used during evaluation of platforms

\begin{tabular}{|c|c|c|c|c|}
\hline Compound & Abbrev. & Potency according to LLNA & Vehicle & GARD input concentration $(\mu \mathrm{M})$ \\
\hline \multicolumn{5}{|l|}{ Sensitizers } \\
\hline 2-Aminophenol & 2-AP & Strong & DMSO & 100 \\
\hline 2-nitro-1,4-phenylenediamine & NPDA & Strong & DMSO & 300 \\
\hline p-Phenylenediamine & PPD & Strong & DMSO & 75 \\
\hline Ethylenediamine & EDA & Moderate & Water & 500 \\
\hline 2-hydroxyethyl acrylate & $2-\mathrm{HA}$ & Moderate & Water & 100 \\
\hline Eugenol & EUG & Weak & DMSO & 300 \\
\hline Geraniol & GER & Weak & DMSO & 500 \\
\hline Penicillin G & PEN G & Weak & Water & 500 \\
\hline \multicolumn{5}{|l|}{ Non-sensitizers } \\
\hline 1-Butanol & BUT & & DMSO & 500 \\
\hline Dimethyl formamide & DF & & Water & 500 \\
\hline Ethyl vanillin & EV & & DMSO & 500 \\
\hline Metyl salicylate & MS & & DMSO & 500 \\
\hline Propylene glycol & $P G$ & & Water & 500 \\
\hline Salicylic acid & SA & & DMSO & 500 \\
\hline \multicolumn{5}{|l|}{ Vehicle controls } \\
\hline Water & $\mathrm{dH}_{2} \mathrm{O}$ & & - & - \\
\hline Dimethyl sulfoxide & DMSO & & - & - \\
\hline
\end{tabular}

List of chemical compounds used for evaluation of platforms. List includes information on sensitizing potency, vehicle, GARD input concentration and abbreviation for each chemical.

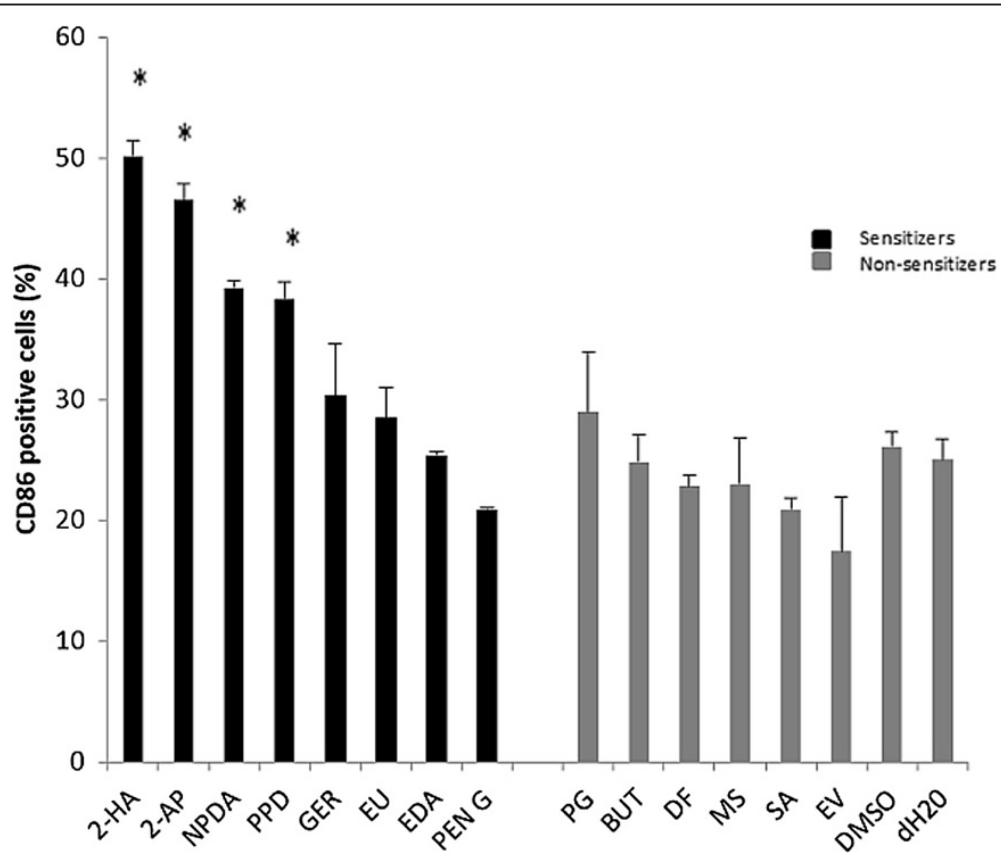

Figure 1 Cell surface expression of CD86 in MUTZ-3 cells after stimulation with sensitizing and non-sensitizing chemicals. Levels of expression of the cell surface marker CD86 were determined using flow cytometry after stimulation with various chemicals for $24 \mathrm{~h}$. Figure illustrates percentage of CD86 positive cells for each chemical $(n=3)$. Gating were performed to exclude dead cells/debris and quadrants were established by comparing with isotype controls. Statistics were performed using Student's t-test $\left({ }^{*} p<0.05\right)$. 
Table 3 List of transcripts used during evaluation of platforms

\begin{tabular}{|c|c|c|c|c|}
\hline Gene symbol & Entrez gene ID & DELTAGene $^{\mathrm{TM}}$ assay ID & NanoString ${ }^{\circledR}$ probe ID & Life technologies $^{T M}$ assay ID \\
\hline ADAM20 & 8748 & GEP00055625 & NM_003814.4:1420 & Hs01083178_s1 \\
\hline CD33 & 945 & GEP00055628 & NM_001177608.1:730 & Hs00233544_m1 \\
\hline CD86 & 942 & GEP00055621 & NM_175862.3:1265 & Hs01567026_m1 \\
\hline CD93 & 22918 & GEA00016079 & NM_012072.3:4270 & Hs00362607_m1 \\
\hline DHCR24 & 1718 & GEA00025118 & NM_014762.2:975 & Hs00207388_m1 \\
\hline DHX33 & 56919 & GEP00055629 & NM_001199699.1:2873 & Hs01063767_m1 \\
\hline FAS & 355 & GEP00055622 & NM_152876.1:1740 & Hs00907759_m1 \\
\hline FASN & 2194 & GEA00032375 & NM_004104.4:5387 & Hs00188012_m1 \\
\hline FDXR & 2232 & GEA00028039 & NM_004110.3:1123 & Hs01031618_g1 \\
\hline GDAP2 & 54834 & GEA00028183 & NM_001135589.1:640 & Hs00214424_m1 \\
\hline GDF11 & 10220 & GEA00006411 & NM_005811.3:3590 & Hs00195156_m1 \\
\hline GNL3L & 54552 & GEA00029786 & NM_001184819.1:1935 & Hs00535521_m1 \\
\hline HIST1H3J & 8356 & GEA00014232 & NM_003535.2:364 & Hs00361917_s1 \\
\hline HMGCS1 & 3157 & GEA00026981 & NM_002130.4:420 & Hs00940429_m1 \\
\hline HNRNPL & 3191 & GEA00029122 & NM_001533.2:757 & Hs00704853_s1 \\
\hline LY96 & 23643 & GEP00055624 & NM_015364.2:360 & Hs01026734_m1 \\
\hline MAPK13 & 5603 & GEP00055633 & NM_002754.3:1050 & Hs00559623_m1 \\
\hline MTR & 4548 & GEA00030234 & NM_000254.2:6816 & Hs00299285_s1 \\
\hline NQO1 & 1718 & GEA00013124 & NM_000903.2:790 & Hs02512143_s1 \\
\hline OR5B21 & 219968 & GEA00014658 & NM_001005218.1:292 & Hs02339238_s1 \\
\hline PFAS & 5198 & GEA00032277 & NM_012393.2:4655 & Hs00389822_m1 \\
\hline PHLDA3 & 23612 & GEA00015249 & NM_012396.3:532 & Hs01926548_s1 \\
\hline$R F C 2$ & 5982 & GEP00055631 & NM_181471.1:835 & Hs00945948_m1 \\
\hline$S F P Q$ & 6421 & GEP00055626 & NM_005066.2:1995 & Hs00192574_m1 \\
\hline SLC37A4 & 2542 & GEP00055634 & NM_001164277.1:1248 & Hs00184616_m1 \\
\hline SQLE & 6713 & GEP00055620 & NM_003129.3:250 & Hs01123768_m1 \\
\hline TLR6 & 10333 & GEA00012581 & NM_006068.2:2530 & Hs00271977_s1 \\
\hline TMEM97 & 27346 & GEP00055627 & NM_014573.2:2055 & Hs00299877_m1 \\
\hline TXNRD1 & 7296 & GEA00013820 & NM_001093771.1:1009 & Hs00917067_m1 \\
\hline$A B C B 4$ & 5244 & GEP00055630 & NM_018849.2:2125 & Hs00240956_m1 \\
\hline GAPDH & 2597 & GEP00055153 & NM_002046.3:972 & Hs03929097_g1 \\
\hline HPRT1 & 3251 & GEP00055483 & NM_000194.1:240 & Hs99999909_m1 \\
\hline
\end{tabular}

A set of 30 transcripts from the GPS was analyzed on all three platforms. Transcripts are listed by gene symbol, Entrez Gene ID, DELTAGene ${ }^{\mathrm{TM}}$ assay ID, NanoString ${ }^{\oplus}$ probe ID and Life Technologies ${ }^{\mathrm{TM}}$ Assay ID. In addition to transcripts from the GPS, three reference transcripts, ABCB4, GAPDH and HPRT1 were analyzed on the evaluated platforms and used for normalization of data.

Methods. Due to issues with a batch of samples during RNA preparation, one of the replicates from the following chemical stimulations had to be removed from analysis on all platforms: p-phenylendiamine, geraniol, eugenol and 1-butanol. In addition, one of the replicates from the following chemical stimulations had to be removed from analysis on nCounter ${ }^{\circ}$ platform due to platform specific issues: 2 -aminophenol and water. Total dataset analyzed on nCounter consisted of 42 samples. In addition to the samples removed due to issues during RNA preparation, one of the replicates from the following chemical stimulations had to be removed from analysis on BioMark $\mathrm{HD}^{\mathrm{ma}}$ and OpenArray platforms due to insufficient amounts of cDNA: propylene glycol, methyl salicylate, geraniol and dimethyl sulfoxide. Total dataset analyzed on BioMark $\mathrm{HD}^{\mathrm{mm}}$ and OpenArray consisted of 40 samples. All stimulations except geraniol was present in at least biological duplicates. For chemical stimulations consisting of two replicates, averaged values were calculated from duplicate reactions instead of on triplicate as applied to remaining stimulations. The total number of sample shared between all platforms comprised 38 samples. 


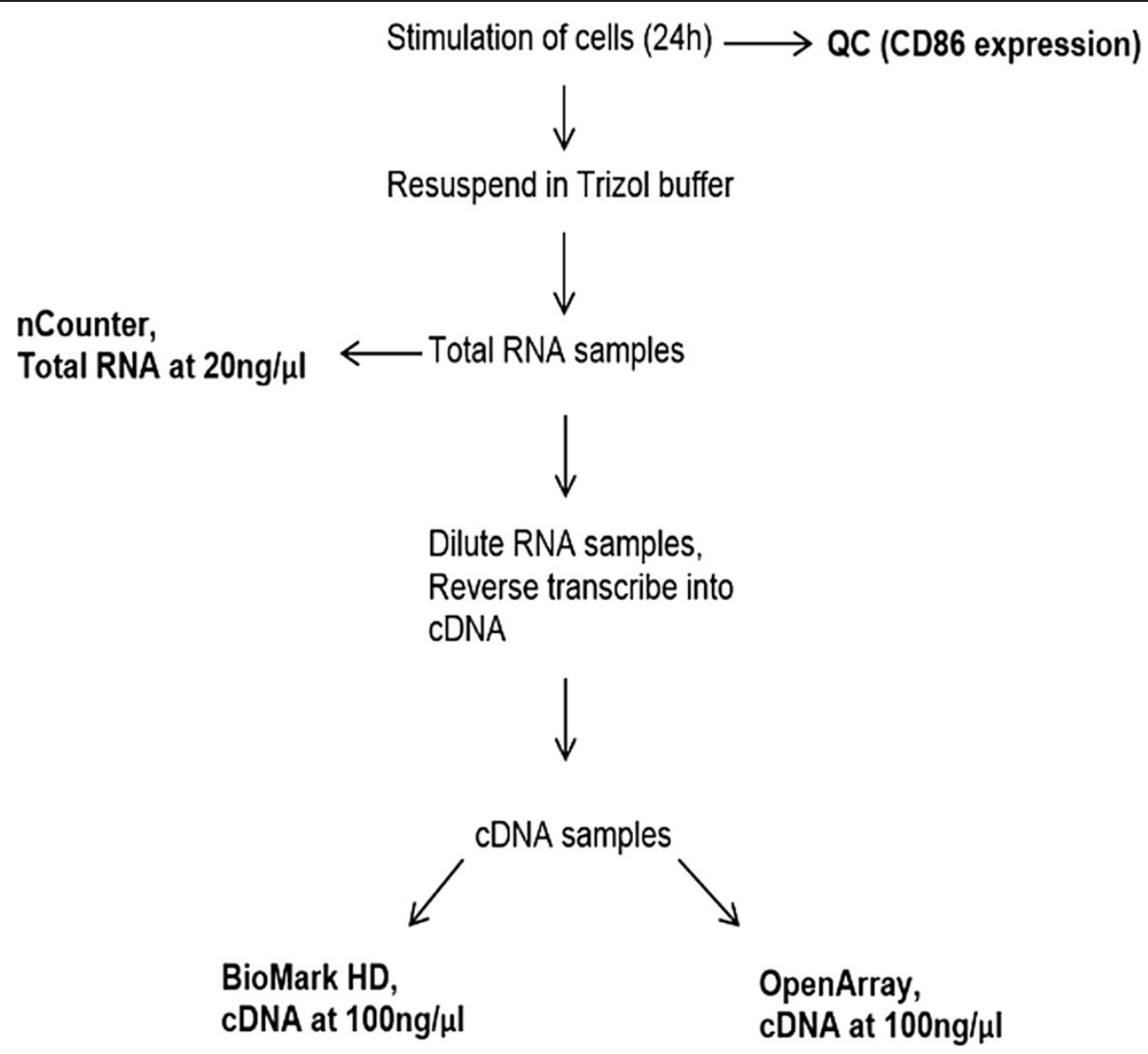

Figure 2 Experimental workflow for evaluation of high throughput platforms. Schematic view of the experimental design illustrating the procedure from chemical stimulation to mRNA quantification on the various platforms.

\section{Detection sensitivity}

To determine how evaluated platforms compared in sensitivity to each other, we estimated the total number of transcripts detected on each platform. Using the set of 38 chemical stimulations shared between all platforms and measuring the expression levels of all 33 transcripts in each stimulation, a total of 1254 transcripts were assayed on each platform. Transcripts were defined as either detected or undetected in a certain chemical stimulation based on platform specific criteria as described in Methods. The overall number of detected transcripts in all samples was higher on the BioMark $\mathrm{HD}^{\mathrm{TM}}$ platform (1246/ 1254) in comparison to both the OpenArray ${ }^{\circ}$ platform $(1210 / 1254)$ and the nCounter ${ }^{\bullet}$ platform (1128/1254). In order to generate a uniform set of transcripts for comparative analysis between the platforms, we chose to include only those transcripts detected in at least two of the three replicate reactions for all stimulations and on all of the evaluated platforms during downstream analysis. Identities and number of detected transcripts for all stimulations and on each platform are summarized in Table 5. While all transcripts were detected in at

Table 4 Comparison of platforms

\begin{tabular}{|c|c|c|c|c|}
\hline Platform & Affymetrix $^{\circledR}$ & nCounter $^{\circledR}$ & BioMark HD ${ }^{\mathrm{TM}}$ & OpenArray $^{\circledR}$ \\
\hline Technology & Microarray & Hybridization & $R T-q P C R$ & RT-qPCR \\
\hline Input material & cDNA & Total RNA & Pre-Amp cDNA & cDNA \\
\hline Sample consumption & 300 ng total RNA/sample & 200 ng total RNA/sample & 125 ng cDNA/sample & 120 ng cDNA/sample \\
\hline Time for analysis & $\begin{array}{l}\sim 4 \text { days from RNA } \\
\text { to results }\end{array}$ & $\begin{array}{l}22 \mathrm{~h} \text { from RNA to results with } \\
\text { a hands on time of } 15 \text { minutes. }\end{array}$ & $\begin{array}{l}7 \mathrm{~h} \text { from cDNA to results with } \\
\text { a hands on time of } \sim 4 \mathrm{~h}\end{array}$ & $\begin{array}{l}3 \mathrm{~h} \text { from cDNA to results with a } \\
\text { hands on time of } 20 \text { minutes. }\end{array}$ \\
\hline Protocols & Difficult & Easy & Medium & Easy \\
\hline Price $^{a}$ & $\$ \$ \$$ & $\$ \$$ & $\$$ & $\$ \$$ \\
\hline
\end{tabular}

Comparison are based on the 48 samples analyzed in the present study. ${ }^{\text {a }}$ Platforms were graded based on total cost to analyze the complete set of 48 samples. The number of $\$$ denotes the relation in costs between the platforms, with the highest number assigned to the most expensive platform. 
Table 5 Comparison of the number of detected genes in the 38 samples shared between all platforms

\begin{tabular}{lccc}
\hline Gene symbol & nCounter $^{\odot}$ & BioMark HD $^{\text {TM }}$ & OpenArray \\
\hline ABCB4 & $1(3 \%)$ & $31(82 \%)$ & $18(47 \%)$ \\
FDXR & $\mathrm{D}$ & $37(97 \%)$ & $36(95 \%)$ \\
OR5B21 & $0(0 \%)$ & $\mathrm{D}$ & $37(97 \%)$ \\
ADAM20 & $11(29 \%)$ & $\mathrm{D}$ & $35(92 \%)$ \\
HIST1H3J & $36(95 \%)$ & $\mathrm{D}$ & $36(95 \%)$ \\
GDF11 & $30(79 \%)$ & $\mathrm{D}$ & $\mathrm{D}$ \\
LY96 & $\mathrm{D}$ & $\mathrm{D}$ & $36(95 \%)$ \\
TLR6 & $36(95 \%)$ & $\mathrm{D}$ & $\mathrm{D}$ \\
CD86 & $33(87 \%)$ & $\mathrm{D}$ & $36(95 \%)$ \\
FASN & $\mathrm{D}$ & $\mathrm{D}$ & $37(97 \%)$ \\
PFAS & $\mathrm{D}$ & $\mathrm{D}$ & $36(95 \%)$ \\
MAPK13 & $37(97 \%)$ & $\mathrm{D}$ & $\mathrm{D}$ \\
GDAP2 & $\mathrm{D}$ & $\mathrm{D}$ & $36(95 \%)$ \\
TMEM97 & $35(92 \%)$ & $\mathrm{D}$ & $\mathrm{D}$ \\
DHX33 & $35(92 \%)$ & $\mathrm{D}$ & $\mathrm{D}$ \\
RFC2 & $\mathrm{D}$ & $\mathrm{D}$ & $37(97 \%)$ \\
ACLY & $\mathrm{D}$ & $\mathrm{D}$ & $35(92 \%)$ \\
TXNRD1 & $\mathrm{D}$ & $\mathrm{D}$ & $37(97 \%)$ \\
HPRT1 & $\mathrm{D}$ & $\mathrm{D}$ & $37(97 \%)$ \\
GAPDH & $\mathrm{D}$ & $\mathrm{D}$ & $37(97 \%)$ \\
\hline Thesef & & $38 \mathrm{hmial}$ & \\
\hline
\end{tabular}

The set of 33 transcripts were measured in the 38 chemical stimulations shared between all platforms. The table illustrates the number of detected calls for a specific transcript across the 38 samples with percentage in parentheses. Table lists only transcripts declared as undetected in any of the stimulations on either $\mathrm{nCounter}{ }^{\oplus}$, BioMark HD ${ }^{\mathrm{TM}}$ or OpenArray ${ }^{\oplus}$. D denotes that transcript is present in all samples.

least two of the three replicates for all stimulations on BioMark $\mathrm{HD}^{\mathrm{mm}}$, one transcript $(A B C B 4)$ on the OpenArray $^{\circ}$ platform, and three transcripts $(A B C B 4$, ORB5B21 and ADAM20) on the nCounter ${ }^{\circ}$ platform, did not fulfill the stringent requirements for use in downstream analysis. Subsequently, ABCB4, ORB5B21 and $A D A M 20$ were removed from the set of transcripts. Two of the removed transcripts, ORB5B21 and $A D A M 20$ originated from the GPS while the transcript $A B C B 4$ was originally considered to be used as a reference gene. All of the removed transcripts were confirmed as low expressed transcripts in the MUTZ-3 cell line based on microarray data (data not shown). The total gene set used for further analysis thus consisted of a total of 28 transcripts from the GPS.

\section{Intra-platform reproducibility and data consistency}

We chose to evaluate precision and to measure data consistency within each platform by calculating coefficient of variation $(\mathrm{CV} \%)$ between biological replicate measurements. Calculations of $\mathrm{CV}$ were performed on intra-platform replicates for each chemical stimulation using quantitative gene expression signals from the subset of 28 transcripts shared between the evaluated platforms. The distribution of replicate $\mathrm{CV}$ values across all transcripts are summarized in a series of box and whiskers plots visualized in Figure 3. All platforms demonstrated good reproducibility of gene expression data. The replicate $\mathrm{CV}$ median values for Affymetrix ${ }^{\circ}$ were the lowest amongst the platforms, ranging from 1-3\% for all chemical stimulations. The replicate $\mathrm{CV}$ median values for the majority of the chemical stimulations measured on nCounter ${ }^{\circ}$, BioMark $\mathrm{HD}^{\mathrm{m}}$ and OpenArray platforms were in the range of $5-15 \%$, although the distribution of replicate $\mathrm{CV}$ varied slightly between various chemical stimulations measured on the same platform. Examples include larger dispersion of replicate $\mathrm{CV}$ values for the stimulations ethyl vanillin, 1-butanol, salicylic acid, methyl salicylate, dimethyl formamide, dimethyl sulfoxide and water in comparison to 2-aminophenol, 2-nitro-1,4-phenylendiamine, p-phenylendiamine and ethylendiamine. However, the pattern of dispersion of the CV values for the different stimulations seems to be comparable across the evaluated platforms.

\section{Inter-platform consistency}

We further evaluated reliability of gene expression data measured on the nCounter ${ }^{\circ}$, BioMark $\mathrm{HD}^{\mathrm{m}}$ and OpenArray ${ }^{\circ}$ platforms by comparing their abilities to measure transcripts in the GARD signature to each other and to Affymetrix ${ }^{\oplus}$ microarrays. Absolute signals of gene expression values generated on the different platforms could not be compared directly since the different platforms utilized different chemistry, quantitation, and normalization methods. Therefore, we evaluated the correlation between data in fold change matrices. Cross-platform comparisons were performed by evaluating concordances of $\log _{2}$ fold changes by pair wise regression analysis of fold differences for chemical stimulations in comparison to vehicle controls. Biological replicate measurements for the 38 samples shared between all platforms were used to calculate the average $\log _{2}$ fold changes across the 28 transcripts present in each stimulation. Dimethyl sulfoxide and water were used as reference samples. The chemical stimulation geraniol was removed from the analysis as no replicate samples were available. This left a dataset consisting of 364 matched measurement pairs (averaged values from 13 stimulations). The matched measurement pairs from each platform were pair-wise plotted against each other and subjected to bivariate analysis. Pearson correlation coefficients and linear fits to the $\log _{2}$ ratios were calculated for each pair-wise platform comparison (Figure 4). Strong correlation was observed between $\log _{2}$ fold change measurements on nCounter ${ }^{\circ}$ and BioMark $\mathrm{HD}^{\mathrm{mm}}$ platforms 


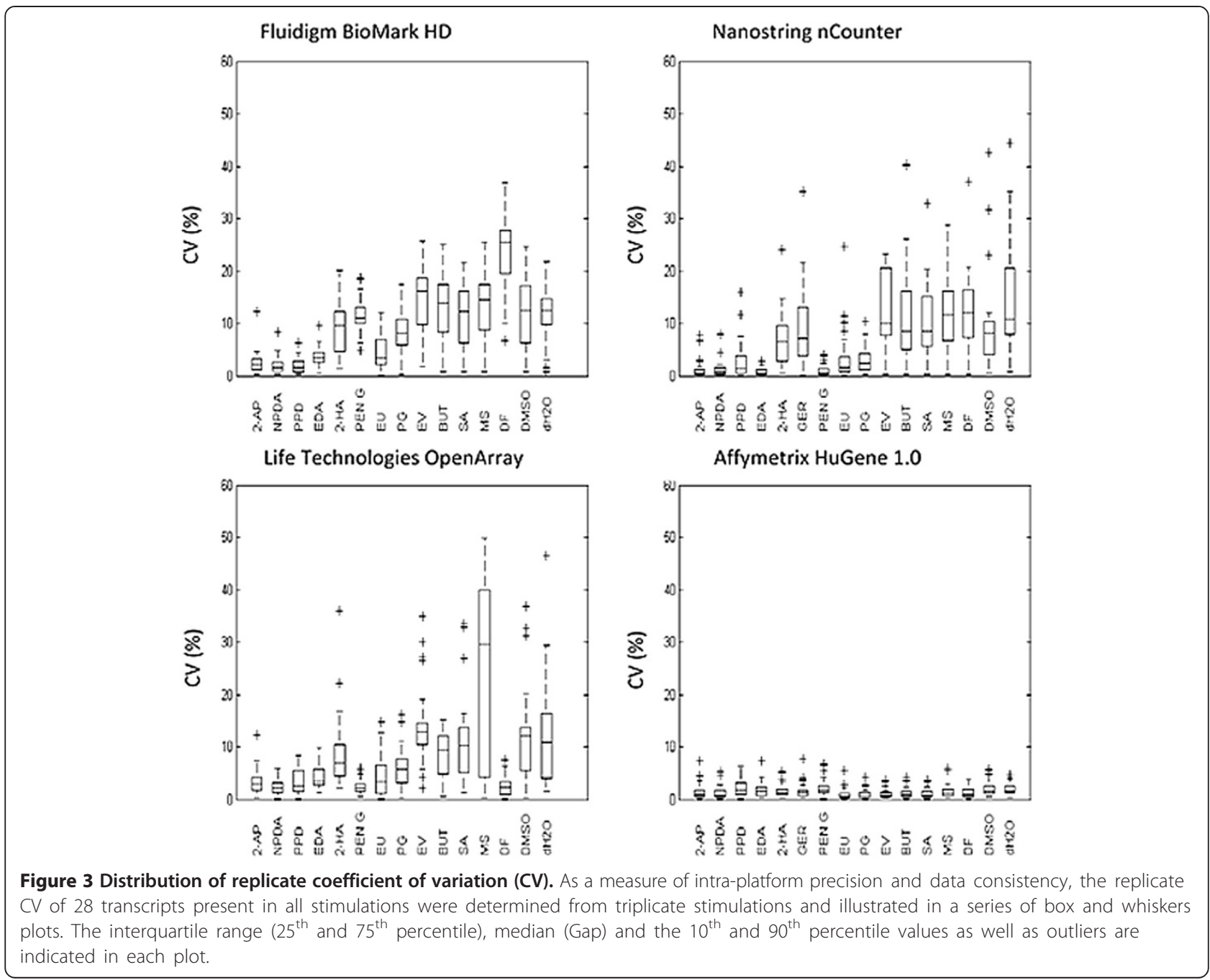

(Figure 4A, $\mathrm{R}=0.84$ ). Lower correlations were observed of either of BioMark $\mathrm{HD}^{\mathrm{mm}}$ (Figure $4 \mathrm{~B}, \mathrm{R}=0.44$ ) or nCounter $^{\circ}$ (Figure $4 \mathrm{C}, \mathrm{R}=0.50$ ) to Affymetrix ${ }^{\circ}$. Low correlations were also observed between $\log _{2}$ fold change measurements of either of BioMark $\mathrm{HD}^{\mathrm{m}}$ (Figure $4 \mathrm{D}, \mathrm{R}=0.53$ ), nCounter ${ }^{\circ}$ (Figure 4E, $\mathrm{R}=0.50$ ) and Affymetrix (Figure 4F, $\mathrm{R}=0.14$ ) with the OpenArray ${ }^{\circ}$ data. Level of compression or expansion of gene expression data measured on the different platforms were evaluated by comparing the slope of the best fitted line of a least square linear regression of the $\log _{2}$ fold changes between pairs of platforms to the ideal slope of 1 . Only a minor compression was observed between nCounter ${ }^{\circ}$ and BioMark $\mathrm{HD}^{\mathrm{ma}}$ (slope: 0.83). Compression effects were observed for both nCounter ${ }^{\circ}$ (slope $=0.33$ ) and BioMark HD $^{\text {tw }}$ (slope 0.35) in relation to OpenArray ${ }^{\circ}$. Affymetrix ${ }^{\circ}$ data compressed $\log _{2}$ fold change measurements relative to the other platforms (slope 0.12, 0.18, 0.040 for BioMark HD, nCounter ${ }^{\ominus}$ and OpenArray ${ }^{\circ}$ respectively).

\section{Comparison of transcriptional profiles from different} platforms as predictive models for skin sensitization

We evaluated overall structure and relevance of gene expression data measured on evaluated high-throughput platforms on a per application basis in order to determine if platforms could be used to distinguish sensitizers from non-sensitizers in the GARD assay. Principal component analysis (PCA) was used to visualize gene expression data from the various platforms. PCA plots were constructed in the software Qlucore Omics Explorer v.2.1 using the subset of 28 transcripts shared between evaluated platforms as variable input. Construction of PCA plots based on the 40 samples in the BioMark $\mathrm{HD}^{\mathrm{max}}$ and OpenArray sample datasets revealed significant outliers that had to be removed, otherwise they would have prevented visualization and classification of separate groups (data not shown). From the BioMark $\mathrm{HD}^{\mathrm{m}}$ data set, one of the replicate of dimethyl formamide had to be removed, leaving a dataset comprising 39 samples. From 


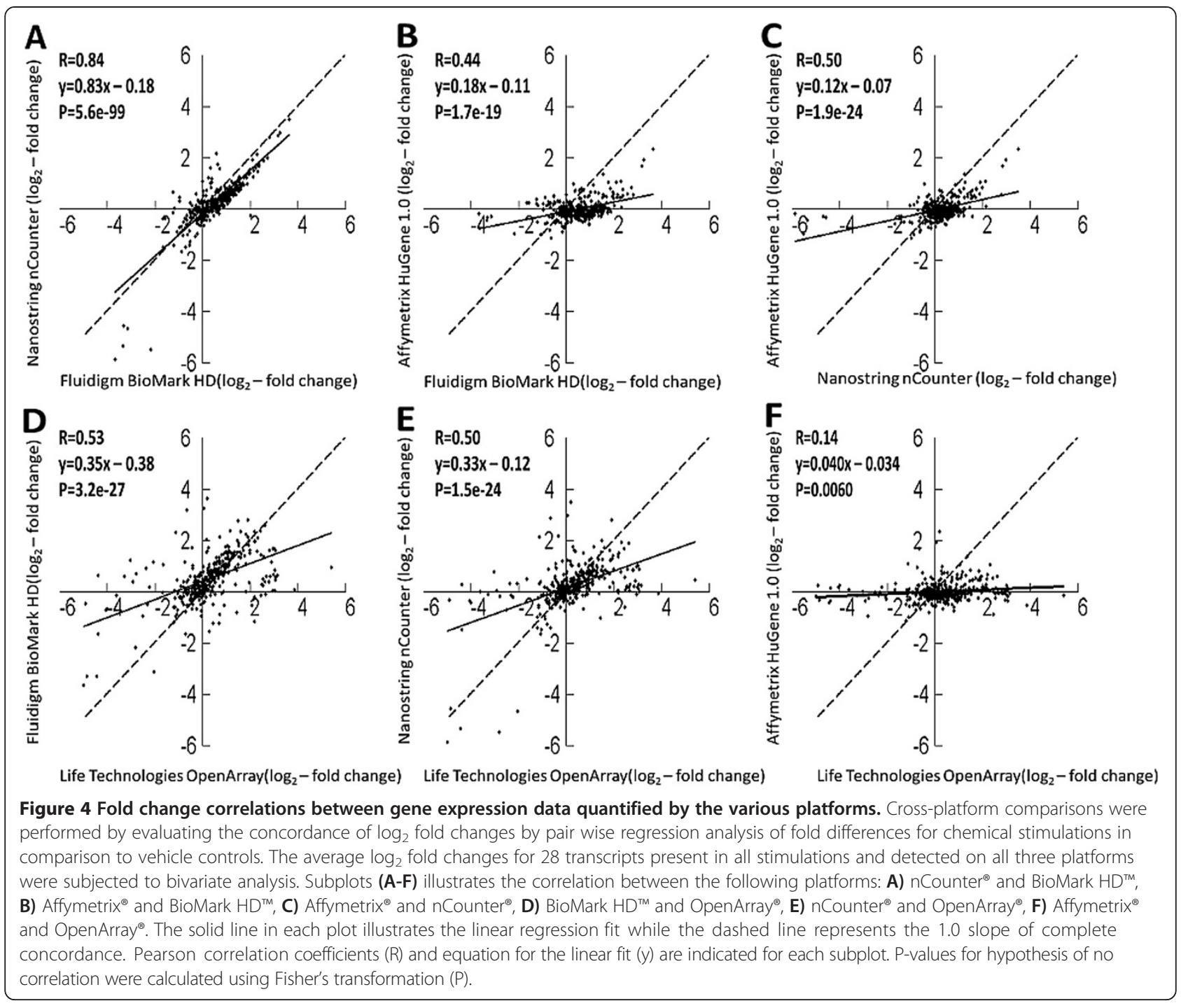

the OpenArray data set, one replicate of dimethyl formamide, 1-butanol, methyl salicylate and water had to be removed, leaving a dataset comprising 36 samples. All 42 samples measured on nCounter ${ }^{\circ}$ were employed for construction of the nCounter ${ }^{\circ}$ PCA plot. For comparative reasons, a PCA plot was constructed based on Affymetrix ${ }^{\circ}$ gene expression measurements of the 48 samples originally selected for this evaluation using the subset of 28 transcripts shared between evaluated platforms as variable input. To determine if gene expression measurements from evaluated platforms could be used to distinguish sensitizers from non-sensitizers, each sample in the PCA plots was colored according to sensitizing potency as defined by the LLNA assay (Figure 5). Neither of the evaluated platforms were able to achieve a complete separation of sensitizers and non-sensitizers. The PCA plot constructed from nCounter ${ }^{\circ}$ data showed highest level of similarity to the Affymetrix ${ }^{\oplus}$ PCA plot. For both these platforms, discrimination between sensitizers and nonsensitizers were seen along the first principal component. While all strong sensitizers clustered together, separated from the non-sensitizers, a few of the moderate and all the weak sensitizers clustered close to the non-sensitizers for the Affymetrix ${ }^{\circ}$ platform, and together with the nonsensitizers for the nCounter ${ }^{\circ}$ platform. The separation profiles for both the BioMark $\mathrm{HD}^{\mathrm{m}}$ and the OpenArray ${ }^{\circ}$ platforms demonstrated a clear discrimination between strong sensitizers and non-sensitizers while a few moderate sensitizers and most weak sensitizers clustered together with non-sensitizers. However, in contrast to the nCounter ${ }^{\circ}$ and the Affymetrix data, discrimination between sensitizers and non-sensitizers was observed along the second principal component. To further investigate the quality and similarity of gene expression data produced on the various platforms for the different chemical stimulations, each sample in the PCA plot was instead 
A Affymetrix HuGene 1.0

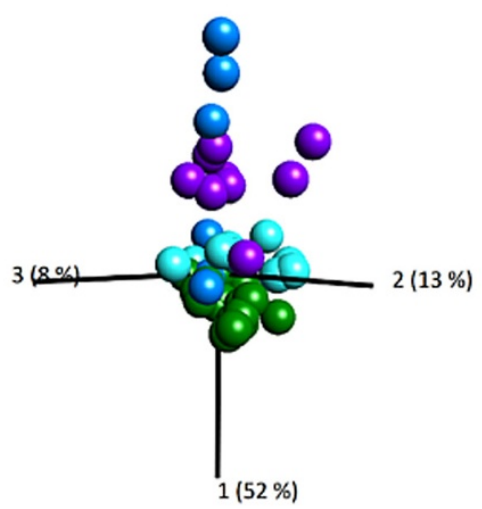

C Fluidigm BioMark HD

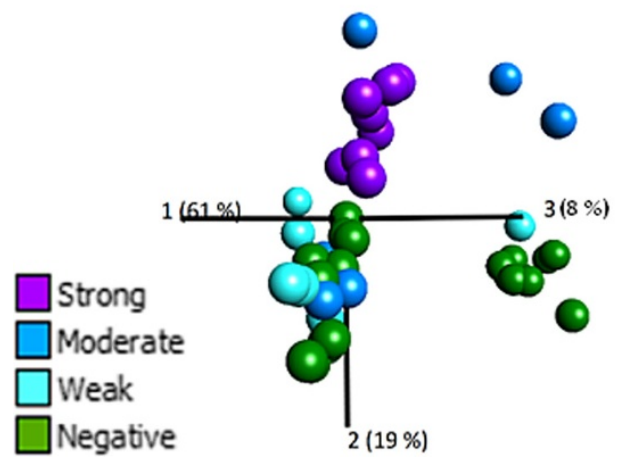

B Nanostring nCounter

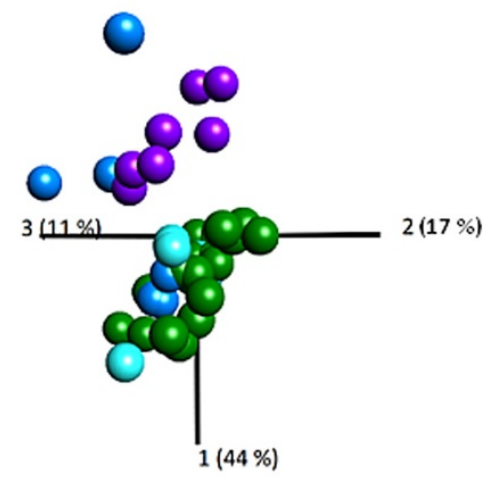

D Life Technologies OpenArray

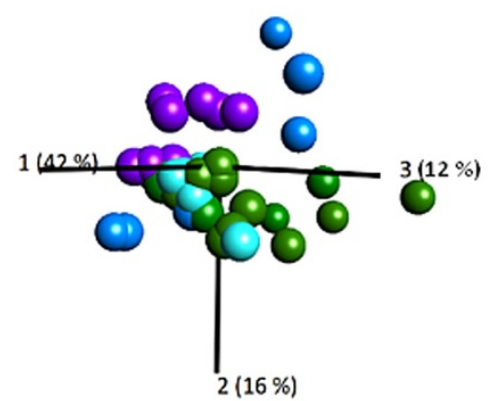

Figure 5 Principal component analysis (PCA) of gene expression data after $\mathbf{2 4} \mathbf{~ h}$ of chemical stimulation. To investigate overall similarities of gene expression data and to outline relevance of data from evaluated platforms for the GARD assay, gene expression data from 28 transcripts shared between all platforms were used for construction of PCA plots in the software Qlucore. Samples were colored according to sensitizing potency as defined by the LLNA assay. Subplots (A-D) illustrates PCA plots constructed from gene expression data obtained on the various platforms. A) Affymetrix ${ }^{\oplus}, 48$ stimulations (weak $(n=9)$, moderate $(n=6)$, strong $(n=9)$, non-sensitizer $(n=24)$ ). B) nCounter ${ }^{\oplus}, 42$ stimulations (weak $(n=7)$, moderate $(n=6)$, strong $(n=7)$, non-sensitizer $(n=22))$. C) BioMark HD, 39 stimulations (weak $(n=6)$, moderate $(n=6)$, strong $(n=8)$, non-sensitizer $(n=19)$. D) OpenArray ${ }^{\oplus}, 36$ stimulations (weak $(n=6)$, moderate $(n=6)$, strong $(n=8)$, non-sensitizer $(n=16)$.

colored according to stimulating agent (Figure 6). Two important observations were made: Firstly, the moderate sensitizer that consistently clustered together with the non-sensitizers for all platforms could be identified as being the same chemical, ethylendiamine. Secondly, replicate stimulations grouped together in all PCA plots, indicating high quality data from all platforms.

\section{Discussion}

The GARD assay was recently developed as an in vitro alternative to animal testing for identification and classification of skin sensitizers. The assay classifies chemicals as either skin sensitizers or non-sensitizers with high accuracy, sensitivity and specificity, using a genomic biomarker signature in the myeloid cell line MUTZ-3. The MUTZ-3 cell line is ideal for assay development as they resemble dendritic cells (DCs) which are important modulators of immune reactions in response to foreign substances [24]. The use of a cell line in the GARD assay ensures a constant supply of cells and enables a large number of cells to be grown via standardized protocols in short time, allowing for a capability to scale up the format of the assay. We believe that the testing strategy behind the GARD assay has potential to replace animal experimentation for classification of chemicals, but that the technical platform currently used for transcriptome analysis, the microarray platform, is a limiting factor for adaption of GARD into a routine assay for analysis and screening of potential sensitizers. To improve GARD and place the assay in a better position for formal validation following an established assessment procedure with the ultimate aims to simplify assay procedures, improve technical parameters and increase sample throughput, we assessed the performance of three high throughput platforms for gene expression measurements and correlated their performance metrics against 


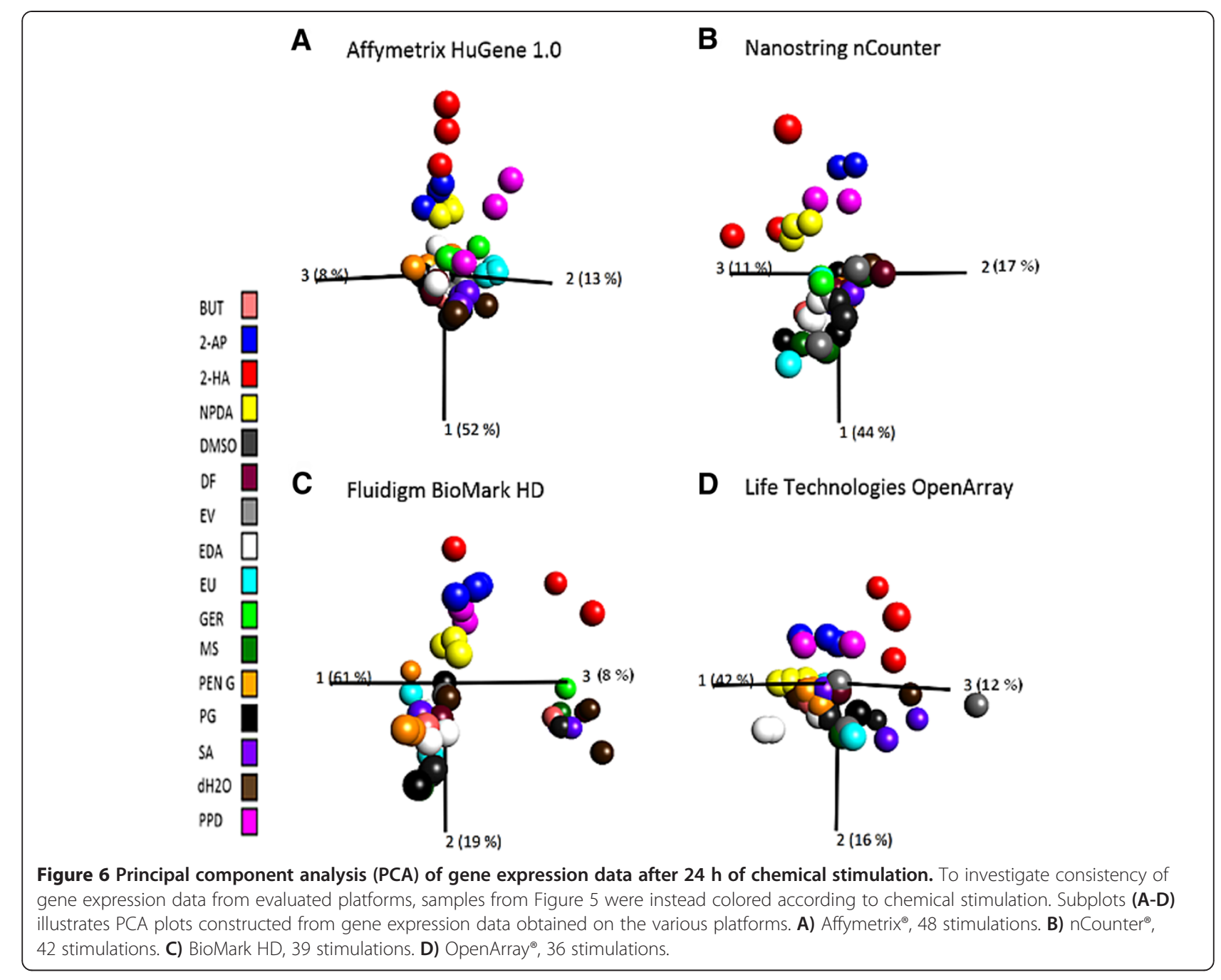

our previously generated microarray data [10]. We measured the levels of 30 representative genes from the GPS across 48 samples on all platforms. Samples comprised 16 chemical stimulations in biological triplicate reactions and included both sensitizers and non-sensitizers. To achieve a comprehensive evaluation, we applied an experimental design allowing us to perform measurements on all platforms from the same chemical stimulation and a single RNA preparation. Thus, only platform-specific protocols downstream from RNA isolation discriminated between measurements on the different platforms.

The key findings from the current study are threefold. Firstly, good intra-platform reproducibility of gene expression data for all platforms was observed. Secondly, all evaluated platforms displayed modest to low correlation of gene expression measurements compared to Affymetrix ${ }^{\circ}$ microarray data. Thirdly, all platforms were able to discriminate most of the extreme and moderate skin sensitizers from non-sensitizers when gene expression data obtained from the various platforms were subjected to PCA analysis.
High intra-platform reproducibility of gene expression measurements was considered a key criterion during the evaluation of platforms. High reproducibility might reduce number of replicates needed for measurements, affecting experimental design, sample throughput and eventually also costs. Considering that evaluated platforms not only use different technology for gene expression measurements but also different protocols for preparation of samples prior to final quantification, we chose to calculate precision based on biological replicate measurements where replicates for each stimulation was prepared individually for analysis according to protocols for a certain platform. Thus, the estimated precision included both technical variations during final measurements as well as variations possibly introduced during sample preparation prior to quantification. The present study demonstrates high intra-platform precision for all platforms. The majority of replicate CV median measurements for nCounter ${ }^{\circ}$, BioMark $\mathrm{HD}^{\mathrm{Tw}}$ and OpenArray ${ }^{\circ}$ were in the range between $5-15 \%$ which was slightly higher than the $\mathrm{CV}$ values observed on the Affymetrix ${ }^{\circ}$ 
platform. In contrast to the $\mathrm{CV}$ values observed on the Affymetrix ${ }^{\oplus}$ platform, the distribution of replicate $C V$ values varies between stimulations on evaluated platforms. The distribution of replicate $\mathrm{CV}$ values for a certain stimulation is however comparable across the evaluated platforms. Considering that a single stimulation was prepared for analysis on nCounter ${ }^{\circ}$, BioMark $\mathrm{HD}^{\mathrm{m}}$ and OpenArray, while Affymetrix ${ }^{\oplus}$ data was based on previously generated data it is likely that the higher CV values observed for the evaluated platforms in comparison to Affymetrix ${ }^{\oplus}$ originate from sample preparation and not from the quantification itself. In addition, evaluated genes were chosen by a datadriven approach, using the Affymetrix ${ }^{\bullet}$ data as an exploratory data set. Thus, the very low $\mathrm{CV}$ values observed for Affymetrix ${ }^{\odot}$ data might be explained by a selection bias. The multiple steps included in sample preparation (RNA to cDNA preparation, data acquisition, normalization of data) are all possible steps for introduction of variations. The nCounter ${ }^{\circledast}$ system has the simplest protocol since measurements can be performed directly on RNA samples and in a single reaction. The OpenArray ${ }^{\circ}$ system requires reverse transcription, but most steps in the analysis is fully automated using a mechanic liquid handler. Finally, the BioMark $\mathrm{HD}^{\mathrm{Tm}}$ system requires both reverse transcription, pre-amplification and several steps of technical pipetting. However, these differences did not seem to affect the reproducibility of the measurement to any large extent as indicated by the similarity in CV values across platforms.

In contrast to reproducibility measurements, we also reported differences in the number of transcripts that could be detected on each of the evaluated platforms. Reasons for not detecting a transcript can be explained by a bad probe for the specific gene or insufficient sample target concentration. Since high frequencies of undetected genes correlated well with low levels of expression, we suggest that the major contribution in this study was due to transcript levels under the limit of detection for the specific platform. Results indicate superior sensitivity of the BioMark $\mathrm{HD}^{\mathrm{im}}$ platform in comparison to both nCounter and OpenArray ${ }^{\ominus}$. The increased detection sensitivity may be linked to the additional cDNA pre-amplification step implemented prior to RT-qPCR on BioMark $\mathrm{HD}^{\mathrm{rm}}$. In contrast, the nCounter ${ }^{\circledast}$ platform does not involve any target amplification and the OpenArray ${ }^{\circ}$ technology involves amplification only during the RT-qPCR reaction when using standard protocols. An unexpected observation was also that the performance of the reference transcripts were different between the platforms (data not shown). While both GAPDH and HPRT1 performed equally well on nCounter ${ }^{\odot}$, only GAPDH performed satisfactory on the BioMark HD ${ }^{\mathrm{sin}}$ and the OpenArray ${ }^{\circ}$ platforms suggesting that care must be taken in selecting appropriate reference genes.

Equally important as reproducibility was to achieve consistency of gene expression measurements across platforms. This would provide a possibility to directly compare new measurements to previous data and to use SVM model trained on historical microarray data for classification of new samples measured on alternative platforms. However, the cross-platform comparison of $\log _{2}$ fold change measurement indicates modest to poor correlation between gene expressions data measured on the different platforms. We suggest that the major contributions to poor correlations are attributable to either platform specific differences in protocols, data processing or differences inherent to each technology. Contributing factors may include slight differences in probe sequences, small differences in the location of probes or primers and the lack of industrial standards across different technologies. Since the selection of primers and probes in this study was based on probe annotations, slight differences in the location of probes or primers on the target sequence might result in the detection of different types of splice variants on the different technologies. Previous experiments have shown that it is possible to achieve improved correlations across platforms using probes matched at exon levels [25]. Other groups have also stated that differences in probes across microarray platforms can be a major cause of discordance [26,27]. We do not have full access to the complete primer and probe sequences for all platforms preventing us from investigating the actual contribution of this factor in this experiment. We feel that the low concordance of gene expression measurements between evaluated platforms and to Affymetrix ${ }^{\circ}$ microarray data will prevent a direct comparison of previously generated microarray data to new measurements on an alternative platform in this type of application.

Finally, we evaluated the overall structure and similarities of gene expression measurements from the various platforms in order to investigate if data from evaluated platforms contained enough biological information to distinguish sensitizers from non-sensitizers in PCA analysis. All platforms were able to distinguish strong sensitizers as well as several of the moderate sensitizers from the non-sensitizers. However, information contained in the gene expression data were not sufficient to distinguish weak sensitizers from non-sensitizers on any of the evaluated platforms. Previous work has reported variations in transcriptional profiles related to the relative potency of stimulating agent [10], indicating a smaller variation between weak sensitizers and non-sensitizers in comparison to strong and moderate sensitizers. Although significant efforts were made in order to select target genes with highest discriminatory power between sensitizers and non-sensitizers in this study, the inability to accurately classify weak sensitizers on the evaluated platforms could potentially be an artifact generated by the smaller number of genes included in this study $(n=28)$ in comparison to the complete GARD signature $(n=200)$. Therefore, we filtered the Affymetrix ${ }^{\bullet}$ data set to include the same genes 
as analyzed by evaluated platforms. Results indicate that the genes selected for this study contains sufficient information to distinguish also the weak sensitizers as the Affymetrix ${ }^{\oplus}$ data illustrated a more obvious separation between weak sensitizers and non-sensitizers in comparison to evaluated platforms (Figure 5). Considering that the GARD signature was initially selected based on Affymetrix ${ }^{\odot}$ microarray data and the poor correlations observed between Affymetrix ${ }^{\oplus}$ and evaluated platforms, we suggested that a reasonable explanation to why evaluated platforms were not able to completely distinguish all sensitizers from all non-sensitizers derives from differences in technology between platforms, i.e., the same factors that contributed to the poor correlation between platforms as discussed above. In support of this argument, the PCA plot constructed from data measured on the hybridization based nCounter ${ }^{\oplus}$ platform shows most similarities to the PCA plot constructed from Affymetrix ${ }^{\oplus}$ data. Alternatively, the observed differentiation between weak sensitizers and non-sensitizers in the Affymetrix ${ }^{\oplus}$ data may also be due to a selection bias, as the Affymetrix ${ }^{\odot}$ data is the historical data set used to identify the genomic predictors. Therefore, we cannot exclude the possibility that including a larger set of genes from the GPS to be analyzed on the evaluated platforms might provide more information relevant for the separation also of weak sensitizer as a larger set of genes would allow for a data driven approach to select for better predictors also on evaluated platforms. In addition, we observed that the separation of sensitizers were seen along the second principal component in PCA plots for gene expression data from the BioMark $\mathrm{HD}^{\mathrm{im}}$ and OpenArray $^{\oplus}$ data instead of along the first principal component as seen with Affymetrix ${ }^{\circledR}$ and nCounter ${ }^{\oplus}$ data. The observed separation along the second principal component indicates that much of the variation in the datasets may be attributable to systematic artifacts from the technologies and not from the transcriptional variations. This has previously been shown for other high-throughput technologies as reviewed by [28].

Other important parameters to consider are price per assay, simplicity of protocols, time to results and sample throughput. These parameters had to be balanced in relation to the technical parameters in order to select a suitable platform for GARD. In comparison to the Affymetrix ${ }^{\oplus}$ platform, evaluated platforms enable higher sample throughput, having shorter turnaround time for results and provides more flexible solutions for focused gene expression of a specific sets of genes. The nCounter ${ }^{\circ}$ platform has the additional advantage of not requiring reverse transcription, being highly multiplexed regarding the amount of transcripts to be measured in a single reaction, requires low amount of hands-on time, provides fully automated liquid handling steps and has the easiest workflow. The BioMark $\mathrm{HD}^{\mathrm{Tm}}$ system is most cost effective and provides a straightforward and simple method for data normalization. The OpenArray system has an easy work flow and streamlined protocol were most liquid handling steps are automated and enables progression from cDNA into results in less than three hours.

In summary, all of the evaluated platforms produced high quality gene expression data, demonstrated acceptable reproducibility of gene expression measurements and retained discriminatory power for separation of strong and moderate sensitizers. Although slight differences between the high-throughput platforms in terms of cost per sample, sample throughput and simplicity of protocols were observed, the evaluated platforms were superior in relation to the microarrays when considering these parameters.

\section{Conclusions}

In this study, we evaluated the performance of three highthroughput platforms using a restricted set of probes from the GARD biomarker signature. We showed that it was possible to achieve acceptable detection sensitivity, reproducibility and discriminatory power between strong and moderate sensitizers and non-sensitizers in the GARD assay and at the same time reduce time to results and assay costs, simplify assay procedures and increase sample throughput by using a high throughput platform. As a final remark, we conclude that all of the evaluated platforms are suitable candidates to replace microarrays as the technical platform for GARD. Changing the platform for gene expression measurement will be a first step in order to prepare GARD for validation and industrial screening of potential sensitizers.

\section{Methods}

\section{Chemicals}

A panel of 16 chemical compounds comprising eight sensitizers and eight non-sensitizers as defined by the LLNA assay were used for stimulation of cells. The sensitizers were 2-aminophenol, 2-nitro-1,4-phenylenediamine, 2hydroxyetylacrylate, p-phenylenediamine, etylenediamine, geraniol, penicillin $G$ and eugenol. The non-sensitizers were propylene glycol, ethyl vanillin, 1-butanol, salicylic acid, methyl Salicylate, dimethyl formamide and the vehicle controls dimethyl sulfoxide and water. All chemicals were purchased from Sigma-Aldrich (St. Louis, MO). Chemical compounds were dissolved in either dimethyl sulfoxide or water [10]. Each chemical compound was diluted into a concentration corresponding to the GARD input concentration. Establishment of GARD input concentration has been extensively described elsewhere $[10,29]$. Sensitizing potency, GARD input concentration and solvents for each chemical compound are summarized in Table 2. 
Cell cultures, phenotypic analysis and chemical stimulations Maintenance, phenotypic analysis and stimulation of the human myeloid leukemia-derived cell line MUTZ-3 were performed as previously described [10]. In short, phenotypic analysis of MUTZ-3 cells was performed using flow cytometry prior to each experiment to ensure that cells were not differentiated. Monoclonal antibodies used during phenotypic analysis: CD1a (DakoCytomation, Glostrup, Denmark), CD34, CD86, HLA-DR (BD Biosciences, Franklin Lakes, NJ), all FITC-conjugated. CD14 (DakoCytomation), CD54, CD80 (BD Biosciences), all PE-conjugated. Propidium iodide (BD Biosciences) was used to estimate cell viability and FITC- and PE- conjugated mouse IgG1 (BD Biosciences) were used as isotype controls. Samples were analyzed on FACSCanto II instrument using FACS Diva software for data acquisition. A total of 10, 000 events were acquired and data were imported into FCS Express V4 (De Novo Software, Los Angeles, CA) for further analysis. Gates were set to exclude non-viable cells and cell debris based on light scattering properties. During chemical stimulation, MUTZ-3 cells were seeded in 24 well-plates and stimulated with chemical compounds. All stimulations were performed in biological triplicates, performed at different time points using different cell cultures. After $24 \mathrm{~h}$ incubation, cells were harvested. Maturity state of the cells were controlled by analyzing cell surface expression of CD86 using flow cytometry as described above. In parallel, harvested cells were lysed in TRIzol $^{\circ}$ reagent (Life Technologies $^{\text {TMx }}$, Carlsbad, CA) and stored at $-20^{\circ} \mathrm{C}$ until RNA extraction.

\section{RNA extraction and CDNA preparation}

RNA was isolated from chemically stimulated MUTZ-3 cells using TRIzol $^{\odot}$ reagent. Purity and concentration of RNA in each sample were confirmed using Agilent Bioanalyzer 2100 (Agilent Technologies, Santa Clara, CA) according to standard protocol provided by the manufacturer. Each sample was diluted into $200 \mathrm{ng} / \mu \mathrm{l}$ of total RNA and divided into two identical $10 \mu \mathrm{l}$ samples $(2 \mu \mathrm{g}$ total RNA). One of the samples was further diluted into $20 \mathrm{ng} / \mu \mathrm{l}$ of total RNA and analyzed on nCounter ${ }^{\bullet}$ platform. The other sample was reverse transcribed into cDNA using the High capacity cDNA reverse transcription kit (Life Technologies $^{\text {Tx }}$ ) according to standard protocols provided by the manufacturer. In short, $10 \mu \mathrm{l}$ of a reverse transcription master mix containing MultiScribe ${ }^{\mathrm{Tm}}$ reverse transcriptase and random primers was prepared for each sample and added to $2 \mu \mathrm{g}$ of total RNA $(10 \mu \mathrm{l}$ at $200 \mathrm{ng} / \mu \mathrm{l})$ for a $20 \mu \mathrm{l}$ reaction. The following thermal protocol was used: $25^{\circ} \mathrm{C}$, $10 \mathrm{~min} ; 37^{\circ} \mathrm{C}, 120 \mathrm{~min} ; 85^{\circ} \mathrm{C}, 5 \mathrm{~min} ; 4^{\circ} \mathrm{C}$ hold. A reaction efficiency of $100 \%$ was assumed. The cDNA samples were divided into two identical $10 \mu \mathrm{l}$ samples and stored at $-20^{\circ} \mathrm{C}$ until further downstream processing for analysis on the BioMark $\mathrm{HD}^{\mathrm{ra}}$ platform and the OpenArray ${ }^{\oplus}$ platform.

\section{Primers and probes}

A total of 33 transcripts were selected for the evaluation. The set of transcripts included 30 genes from GPS as well as three reference genes $(A B C B 4, H P R T 1, G A P D H)$ for normalization of data. A probe set targeting the 33 transcripts was obtained from NanoString ${ }^{\oplus}$ (NanoString Technologies, Seattle, WA) for analysis on the nCounter platform. Pairs of primers targeting the same 33 transcripts were obtained from DELTAGene ${ }^{\mathrm{Tm}}$ (Fluidigm ${ }^{\bullet}$, San Francisco, $\mathrm{CA}$ ) for analysis on the BioMark $\mathrm{HD}^{\mathrm{T \mu}}$ platform. DELTAGene $^{\mathrm{TM}}$ quantification of gene expression was based on $\mathrm{SYBR}^{\circ}$ Green hybridization chemistry. Pairs of primers and probes targeting the same 33 transcripts were obtained from Life Technologies ${ }^{\mathrm{TM}}$ (Life Technologies ${ }^{\mathrm{TM}}$, Carlsbad, CA) for analysis on the OpenArray platform. OpenArray ${ }^{\circ}$ quantification of gene expression was based on TaqMan ${ }^{\circ}$ hydrolysis chemistry. A complete list of accession numbers for transcripts is provided in Table 3.

\section{Measurement of gene expression on nCounter ${ }^{\circledast}$ system}

Total RNA samples from chemically stimulated MUTZ-3 cells, prepared as described above, were sent to NCCR Frontiers in Genetics (Geneva, Switzerland) on dry ice for analysis on the nCounter ${ }^{\bullet}$ system. An amount of $200 \mathrm{ng}$ $(10 \mu \mathrm{l})$ of total RNA from each sample was analyzed on the nCounter ${ }^{\circ}$ system using standardized protocol for gene expression analysis provided by NanoString ${ }^{\bullet}$ Each sample was analyzed in a separate multiplexed reaction. Data was imported into nSolver ${ }^{\mathrm{Tm}}$ analysis software using NanoString ${ }^{\odot}$ raw code count collector tool. Normalization of data was performed according to NanoString analysis guidelines. For negative control normalization, the mean of the counts for all negative controls in each sample plus two standard deviations was subtracted from counts for the remaining transcripts in same sample. For positive control normalization, a normalization reference was first generated by calculating the sum of the counts for the positive spike in transcripts in each sample and then calculating the average of these sums across all samples. A scaling factor for each sample was then calculated by dividing the sum of the counts from the positive spike in transcripts from each sample with the normalization reference. Remaining code counts were multiplied by the sample specific scaling factor. Normalized counts were compiled into Microsoft Excel and further normalized against the reference genes GAPDH and HPRT1. For normalization to reference genes, the geometric mean of the counts for GAPDH and HPRT1 for each sample was calculated, and the average across all samples was used as the normalization reference. A scaling factor for normalization of remaining code counts was calculated and applied as described above for positive control normalization. Reference genes were selected based on internal control parameters included in an nSolver Excel macro developed by NCCR Frontiers in Genetics using the 
geNorm method [30]. For a gene to be considered as detected, the normalized gene counts for a specific transcript had to be significantly (Student's t test, $\mathrm{p}<0.05$ ) above background threshold count value for the negative controls.

\section{Measurement of gene expression on BioMark ${ }^{\mathrm{TM}} \mathrm{HD}$ system} Specific Target Amplification (STA) was performed on cDNA samples using TaqMan ${ }^{\bullet}$ PreAmp Master Mix (Life Technologies $^{\mathrm{TM}}$ ) and standard protocols provided by manufacturer. In short, $1.25 \mu \mathrm{l}$ of each cDNA sample was combined with $2.5 \mu \mathrm{l}$ of $2 \mathrm{x}$ TaqMan PreAmp Master Mix in wells of a 96-well PCR plate. $0.5 \mu \mathrm{l}$ of a preamplification primer mix comprising a mixture of pooled DELTAGene $^{\mathrm{TM}}$ assays (500nM of each primer) was mixed

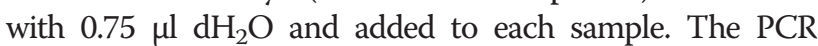
plate was transferred to a thermal cycler and subjected to the following thermal protocol: $95^{\circ} \mathrm{C}, 10 \mathrm{~min} ; 14$ cycles $\left(95^{\circ} \mathrm{C}, 15 \mathrm{~s} ; 60^{\circ} \mathrm{C}, 4 \mathrm{~min}\right) ; 4^{\circ} \mathrm{C}$ hold. Samples were treated with Exonuclease I (New England BioLabs, Ipswich, MA) to remove unincorporated primers by adding $2 \mu \mathrm{l}$ (at $4 \mathrm{U} / \mu \mathrm{l}$ ) to each STA reaction. The PCR plate was once again transferred to a thermal cycler and subjected to the following thermal protocol: $37^{\circ} \mathrm{C}, 30 \mathrm{~min} ; 80^{\circ} \mathrm{C}, 15 \mathrm{~min} ; 4^{\circ} \mathrm{C}$ hold. All samples were then diluted $10 \times$ in TE-buffer $(10 \mathrm{mM}$ Tris$\mathrm{HCl}, 0.1 \mathrm{mM}$ EDTA, $\mathrm{pH}$ 8) (Sigma-Aldrich) and sent to Veterinærinstituttet (DTU, Copenhagen, Denmark) on dry ice for analysis on the BioMark $\mathrm{HD}^{\mathrm{TM}}$ system. Operation of instruments and handling and processing of the IFC controller HX were performed using standardized protocol for gene expression analysis provided by Fluidigm ${ }^{\circ}$. Samples were prepared for loading on a 96:96 Dynamic array ${ }^{\text {TM }}$ IFC by combining $2.25 \mu \mathrm{l}$ of each preamplified cDNA sample with $2.5 \mu \mathrm{l} 2 \times$ SsoFast $^{\mathrm{Tm}}$ EvaGreen $^{\circ}$ Supermix with low ROX (BioRad, Hercules, CA) and $0.25 \mu \mathrm{l} 20 \times$ DNA binding dye loading reagent (Fluidigm ${ }^{\circ}$ ). A total of $5 \mu \mathrm{l}$ of each pre amplified cDNA sample and $5 \mu \mathrm{l}$ of each DeltaGene assay were dispensed into their corresponding inlets on the Dynamic array $^{\mathrm{TM}}$ and samples were subjected to RT-qPCR reaction using the following thermal cycling protocol: $70^{\circ} \mathrm{C}, 40 \mathrm{~min}$; $60^{\circ} \mathrm{C}, 30 \mathrm{~s} ; 95^{\circ} \mathrm{C}, 1 \mathrm{~min} ; 35$ cycles $\left(96^{\circ} \mathrm{C}, 5 \mathrm{~s} ; 60^{\circ} \mathrm{C}, 20 \mathrm{~s}\right)$ and melting curve using a ramp from $60^{\circ} \mathrm{C}$ to $95^{\circ} \mathrm{C}$ at $1^{\circ} \mathrm{C} / 3 \mathrm{~s}$. Data was collected with Fluidigm ${ }^{\circ}$ Real-Time PCR analysis software using linear baseline correction method and global auto $\mathrm{Cq}$ threshold method. Normalizations of data were performed using comparative $\mathrm{Cq}$ method [31]. The reference gene used in this study, GAPDH, was selected based on internal control parameters included in software. A transcript was considered as undetected in a certain chemical stimulation when unprocessed $\mathrm{Cq}$ value exceeded 35 .

\section{Measurement of gene expression on OpenArray ${ }^{\circledR}$ system} cDNA samples from chemically stimulated MUTZ-3 cells, prepared as described above, were sent to Life Technologies ${ }^{\mathrm{TM}}$ demo laboratory (Saint Aubin, France) on dry ice for analysis on the OpenArray ${ }^{\oplus}$ system. Loading of samples, operation of instruments and RT-qPCR cycling were performed using standardized protocol for gene expression analysis provided by Life Technologies ${ }^{\mathrm{Ts}}$. In short, $1.2 \mu \mathrm{l}$ of each cDNA sample was combined with $2.5 \mu$ l of $2 \times$ TaqMan $^{\bullet}$ OpenArray $^{\circ}$ Real-Time PCR Master Mix (Life Technologies ${ }^{\mathrm{Tm}}$ ) and $1.3 \mu \mathrm{ld} \mathrm{d}_{2} \mathrm{O}$ and transferred to an OpenArray ${ }^{\circ} 384-$ Well Sample Plate. Samples were loaded into the custom designed OpenArray ${ }^{\oplus}$ plates using QuantStudio ${ }^{\text {тм }} 12 \mathrm{~K}$ flex AccuFill $^{\mathrm{TM}}$ system. The OpenArray ${ }^{\oplus}$ plates were removed from the AccuFill ${ }^{\mathrm{TM}}$ system, transferred to an OpenArray ${ }^{\circ}$ carrier, covered with immersion fluid (All reagents from QuantStudio $^{\mathrm{Tm}} 12 \mathrm{~K}$ flex OpenArray ${ }^{\circ}$ accessories kit, Life Technologies $^{\mathrm{TM}}$ ) and loaded into the QuantStudio ${ }^{\mathrm{Tm}} 12 \mathrm{~K}$ flex instrument for RT-qPCR cycling. Samples were subjected to standard thermal cycling protocol provided by Life technologies $^{\mathrm{Tm}}$. Data was collected with Life Technologies ${ }^{\mathrm{TM}}$ Expression Suit analysis software v 1.0.3 using linear baseline correction method and the global auto Cq threshold method. Normalization of data was performed using the comparative $\mathrm{Cq}$ method [31]. The reference gene used in this study, GAPDH was selected based on internal control parameters included in software. A transcript was considered as undetected in a certain chemical stimulation when unprocessed Cq value exceeded 35.

\section{Measurement of gene expression on Affymetrix ${ }^{\circledR}$ HuGene 1.0 ST arrays}

Affymetrix ${ }^{\odot}$ gene expression data used for comparative analyses in this study was obtained from previously published experiments [10]. Maintenance, phenotypic analysis and stimulation of cells were carried out as described above. Preparation of cDNA, hybridization, washing and scanning of Human Gene 1.0 ST Arrays (Affymetrix ${ }^{\oplus}$, Santa Clara, CA) as well as RMA normalization of data was performed according to standardized protocol provided by the manufacturer (Affymetrix ${ }^{\odot}$ ) and as previously described [10]. Gene expression data was filtered to contain only the 30 genes from the 16 chemical compound stimulations as analyzed by nCounter ${ }^{\circ}$, BioMark $\mathrm{HD}^{\mathrm{TM}}$ and OpenArray ${ }^{\circ}$.

\section{Inter-platform consistency}

Inter-platform consistency was measured by pair-wise plotting of averaged $\log _{2}$ fold change data of gene expression measurements obtained on the various platforms. Results were evaluated by calculating Pearson correlation coefficient and linear fits to the $\log _{2}$ fold change ratios. Expression ratios were calculated as follows:

$$
\begin{aligned}
& \log _{2} \mathrm{FC}_{\text {Affymetrix }}{ }^{\circledR}=\mu_{\text {sample }}-\mu_{\text {control }} \\
& \log _{2} \mathrm{FC}_{\text {nCounter } \circledast}=\log _{2}\left(\mu_{\text {sample }} / \mu_{\text {control }}\right)
\end{aligned}
$$




$$
\begin{aligned}
& \log _{2} \mathrm{FC}_{\text {BioMark } \mathrm{HD}^{\mathrm{m}}} \text { and } \log _{2} \mathrm{FC}_{\text {OpenArray }} \\
& \quad=-\left(\Delta \mathrm{Cq}_{\text {sample }}-\Delta \mathrm{Cq}_{\text {control }}\right)
\end{aligned}
$$

Where $\mu_{\text {sample }}$ is the normalized mean for chemically stimulated samples and $\mu_{\text {control }}$ is the normalized mean for vehicle controls. For PCR-based methods, $\Delta$ Cq $\mathrm{q}_{\text {sample }}$ is the normalized mean quantification cycle for chemically stimulated samples and $\Delta \mathrm{Cq}_{\text {control }}$ is the normalized mean quantification cycle for vehicle control. Calculations accounts for the fact that $\mathrm{Cq}$ values obtained from the RT-qPCR methods as well as the RMA normalized Affymetrix ${ }^{\circ}$ data were already in log-space.

\section{Comparison of transcriptional profiles}

Normalized gene expression measurements from each platform were compiled into the software Qlucore Omics Explorer 2.1 (Qlucore AB, Lund, Sweden). Gene expression data was filtered to include only those genes detected in at least two of the three replicates. Data was investigated and visualized using Principal Component Analysis.

\section{Competing interests}

The authors declare that they have no competing interests.

\section{Authors' contributions}

$M L, H J$ and $A F$ designed the study. ML and $H J$ supervised the project. AF performed the experiments, prepared the figures and wrote the manuscript $\mathrm{AF}$ and AA analyzed the gene expression data and performed the statistical analysis. All authors have read and approved the manuscript.

\section{Acknowledgements}

This work was supported by grants from the Swedish Fund for Research Without Animal Experiments, Vinnova, the Swedish Research Council, Swedish Research Council Formas and the Faculty of Engineering (LTH). We would like to thank Ann-Charlott Olsson for technical support and microarray sample preparation.

Received: 7 January 2014 Accepted: 2 May 2014

Published: 16 May 2014

\section{References}

1. Akhavan A, Cohen SR: The relationship between atopic dermatitis and contact dermatitis. Clin Dermatol 2003, 21(2):158-162.

2. Fonacier LS, Dreskin SC, Leung DY: Allergic skin diseases. J Allergy Clin Immunol 2010, 125(2 Suppl 2):S138-S149.

3. Karlberg AT, Bergstrom MA, Borje A, Luthman K, Nilsson JL: Allergic contact dermatitis-formation, structural requirements, and reactivity of skin sensitizers. Chem Res Toxicol 2008, 21(1):53-69.

4. Thyssen JP, Linneberg A, Menne T, Johansen JD: The epidemiology of contact allergy in the general population-prevalence and main findings. Contact Dermatitis 2007, 57(5):287-299.

5. Peiser M, Tralau T, Heidler J, Api AM, Arts JH, Basketter DA, English J, Diepgen TL, Fuhlbrigge RC, Gaspari AA, Johansen JD, Karlberg AT, Kimber I, Lepoittevin JP, Liebsch M, Maibach HI, Martin SF, Merk HF, Platzek T, Rustemeyer T, Schnuch A, Vandebriel RJ, White IR, Luch A: Allergic contact dermatitis: epidemiology, molecular mechanisms, in vitro methods and regulatory aspects. Current knowledge assembled at an international workshop at BfR, Germany. Cell Mol Life Sci 2012, 69(5):763-781.

6. Diepgen $T L$, Coenraads PJ: The epidemiology of occupational contact dermatitis. Int Arch Occup Environ Health 1999, 72(8):496-506.

7. Diepgen TL: Occupational skin-disease data in Europe. Int Arch Occup Environ Health 2003, 76(5):331-338.
8. Basketter DA, Evans P, Fielder RJ, Gerberick GF, Dearman RJ, Kimber I: Local lymph node assay - validation, conduct and use in practice. Food Chem Toxicol 2002, 40(5):593-598

9. European Parliament, Council of the European Union: REGULATION (EC) No $1223 / 2009$ of the European parliament and of the council of 30 November 2009 on cosmetic products. Official J European Union 2009, L342:59-209.

10. Johansson H, Lindstedt M, Albrekt AS, Borrebaeck CA: A genomic biomarker signature can predict skin sensitizers using a cell-based in vitro alternative to animal tests. BMC Genomics 2011, 12:399.

11. Noble WS: What is a support vector machine? Nat Biotechnol 2006, 24(12):1565-1567.

12. Murphy D: Gene expression studies using microarrays: principles, problems, and prospects. Adv Physiol Educ 2002, 26(1-4):256-270.

13. Draghici S, Khatri P, Eklund AC, Szallasi Z: Reliability and reproducibility issues in DNA microarray measurements. Trends Genet 2006, 22(2):101-109

14. Liang P: MAQC papers over the cracks. Nat Biotechnol 2007, 25(1):27-28. author reply 28-29.

15. Larkin JE, Frank BC, Gavras H, Sultana R, Quackenbush J: Independence and reproducibility across microarray platforms. Nat Methods 2005, 2(5):337-344.

16. OECD: OECD Series on Testing and Assessment No 34. Guidance Document on the Validation and International Acceptance of New or Updated Test Methods for Hazard Assessment. Paris, France: Organisation for Economic Cooperation and Development; 2005:96

17. Geiss GK, Bumgarner RE, Birditt B, Dahl T, Dowidar N, Dunaway DL, Fell HP, Ferree S, George RD, Grogan T, James JJ, Maysuria M, Mitton JD, Oliveri P, Osborn JL, Peng T, Ratcliffe AL, Webster PJ, Davidson EH, Hood L, Dimitrov $\mathrm{K}$ : Direct multiplexed measurement of gene expression with color-coded probe pairs. Nat Biotechnol 2008, 26(3):317-325.

18. Spurgeon SL, Jones RC, Ramakrishnan R: High throughput gene expression measurement with real time PCR in a microfluidic dynamic array. PLOS One 2008, 3(2):e1662

19. Morrison T, Hurley J, Garcia J, Yoder K, Katz A, Roberts D, Cho J, Kanigan T, Ilyin SE, Horowitz D, Dixon JM, Brenan CJ: Nanoliter high throughput quantitative PCR. Nucleic Acids Res 2006, 34(18):e123.

20. Mackay IM, Arden KE, Nitsche A: Real-time PCR in virology. Nucleic Acids Res 2002, 30(6):1292-1305.

21. Shi L, Tong W, Fang H, Scherf U, Han J, Puri RK, Frueh FW, Goodsaid FM, Guo L, Su Z, Han T, Fuscoe JC, Xu ZA, Patterson TA, Hong H, Xie Q, Perkins RG, Chen JJ, Casciano DA: Cross-platform comparability of microarray technology: intra-platform consistency and appropriate data analysis procedures are essential. BMC Bioinforma 2005, 6(Suppl 2):S12.

22. Brenan C, Morrison T: High throughput, nanoliter quantitative PCR. Drug Discovery Today 2005, 2(3):247-253.

23. Hu ZB, Ma W, Zaborski M, MacLeod R, Quentmeier H, Drexler HG: Establishment and characterization of two novel cytokine-responsive acute myeloid and monocytic leukemia cell lines, MUTZ-2 and MUTZ-3. Leukemia 1996, 10(6):1025-1040.

24. Santegoets SJ, Masterson AJ, van der Sluis PC, Lougheed SM, Fluitsma DM, van den Eertwegh AJ, Pinedo HM, Scheper RJ, de Gruijl TD: A CD34(+) human cell line model of myeloid dendritic cell differentiation: evidence for a CD14(+)CD11b(+) Langerhans cell precursor. J Leukoc Biol 2006, 80(6):1337-1344

25. Kuo WP, Liu F, Trimarchi J, Punzo C, Lombardi M, Sarang J, Whipple ME, Maysuria M, Serikawa K, Lee SY, McCrann D, Kang J, Shearstone JR, Burke J, Park DJ, Wang X, Rector TL, Ricciardi-Castagnoli P, Perrin S, Choi S, Bumgarner R, Kim JH, Short GF III, Freeman MW, Seed B, Jensen R, Church GM, Hovig E, Cepko CL, Park P, et al: A sequence-oriented comparison of gene expression measurements across different hybridization-based technologies. Nat Biotechnol 2006, 24(7):832-840.

26. Shippy R, Sendera TJ, Lockner R, Palaniappan C, Kaysser-Kranich T, Watts G, Alsobrook J: Performance evaluation of commercial short-oligonucleotide microarrays and the impact of noise in making cross-platform correlations. BMC Genomics 2004, 5:61.

27. Canales RD, Luo Y, Willey JC, Austermiller B, Barbacioru CC, Boysen C, Hunkapiller K, Jensen RV, Knight CR, Lee KY, Ma Y, Maqsodi B, Papallo A, Peters EH, Poulter K, Ruppel PL, Samaha RR, Shi L, Yang W, Zhang L, Goodsaid FM: Evaluation of DNA microarray results with quantitative gene expression platforms. Nat Biotechnol 2006, 24(9):1115-1122. 
28. Ringner M: What is principal component analysis? Nat Biotechnol 2008, 26(3):303-304.

29. Johansson H, Albrekt AS, Borrebaeck CA, Lindstedt M: The GARD assay for assessment of chemical skin sensitizers. Toxicol In Vitro 2013, 27(3):1163-1169.

30. Vandesompele J, De Preter K, Pattyn F, Poppe B, Van Roy N, De Paepe A, Speleman F: Accurate normalization of real-time quantitative RT-PCR data by geometric averaging of multiple internal control genes. Genome Biol 2002 3(7):research0034-research0034.11. doi:10.1186/gb-2002-3-7-research0034.

31. Livak KJ, Schmittgen TD: Analysis of relative gene expression data using real-time quantitative PCR and the 2(-Delta Delta C(T)) Method. Methods 2001, 25(4):402-408

doi:10.1186/1471-2164-15-379

Cite this article as: Forreryd et al:: Evaluation of high throughput gene expression platforms using a genomic biomarker signature for prediction of skin sensitization. BMC Genomics 2014 15:379.

\section{Submit your next manuscript to BioMed Central and take full advantage of:}

- Convenient online submission

- Thorough peer review

- No space constraints or color figure charges

- Immediate publication on acceptance

- Inclusion in PubMed, CAS, Scopus and Google Scholar

- Research which is freely available for redistribution 